\title{
Total Synthesis of the Post-translationally Modified Polyazole Peptide
}

\section{Antibiotic Plantazolicin A}

\author{
Hiroki Wada, Huw E. L. Williams and Christopher J. Moody*a] \\ School of Chemistry, University of Nottingham, Nottingham NG7 2RD, U.K. \\ E-mail: c.j.moody@nottingham.ac.uk
}

\begin{abstract}
The power of rhodium carbene methodology in chemistry is demonstrated by the synthesis of a structurally complex polyazole antibiotic. Plantazolicin A, a novel soil bacterium metabolite, comprises a linear array of 10 five-membered rings in two pentacyclic regions that derive from ribosomal peptide synthesis followed by extensive post-translational modification. The compound possesses potent antimicrobial activity, and is selectively active against the anthrax causing organism. A conceptually different synthesis of plantazolicin $A$ is reported in which the key steps are the use of rhodium(II)-catalyzed reactions of diazocarbonyl compounds to generate up to six of the seven oxazole rings of the antibiotic. NMR Spectroscopic studies and molecular modeling, reveal a likely dynamic hairpin conformation with a hinge region around the two isoleucine residues. The compound has modest activity against methicillin-resistant Staphylococcus aureus (MRSA).
\end{abstract}

In the one and a half centuries since August Kekule and Archibald Scott Couper independently proposed that a carbon atom could form four bonds to other atoms (including other carbons), ${ }^{[1,2]}$ the existence of divalent carbons species with a 6-electron valence shell has intrigued chemists. Once regarded as mechanistic curiosities or fleeting intermediates, such divalent species, now known as carbenes, have moved center stage as a result of the isolation of the first stable carbene in the late $1980 \mathrm{~s},{ }^{[3]}$ to be followed by the now familiar stable N-heterocyclic carbenes, ${ }^{[4]}$ that as ligands have revolutionalized transition-metal catalysis. ${ }^{[5]}$ Also metallocarbene intermediates, derived from diazo compounds, participate in a plethora of reactions that are useful in chemical synthesis. ${ }^{[6]}$ We now demonstrate the power of carbene chemistry in the synthesis of the structurally unique, complex polyazole antibiotic plantazolicin $A$, in which upto six of the seven 5-membered oxazole rings of the natural product originate from simple precursors such as carboxamides or nitriles facilitated by carbene methodology (Scheme 1). ${ }^{[7-10]}$

Plantazolicin A 1 and plantazolicin B 2 are novel metabolites isolated from the soil bacterium Bacillus amyloliquefaciens FZB42. ${ }^{[1,12]}$ The structures consist of a linear array of 5-membered rings (azoles) that biosynthetically derive from amino acids by ribosomal peptide synthesis followed by wide-ranging posttranslational modification. ${ }^{[13-15]}$ However, it is the potent antimicrobial activity of plantazolicin A against Gram positive organisms that has attracted much attention. In particular, the compound is selectively active against the anthrax causing organism Bacillus anthracis (Sterne). ${ }^{[11,13]}$ Although the polyazole nature of plantazolicin $A$ is highly reminiscent of the thiopeptide antibiotics, ${ }^{[16-18]}$ a synthetic derivative of which has entered the clinic against Clostridium difficile infections, ${ }^{[19,20]}$ there are key differences. Specifically, the linear nature of the antibiotic with its two pentacyclic regions represents a challenge for chemical synthesis that, in combination with the antimicrobial activity, makes plantazolicin A highly attractive for further study. In this regard, the first total synthesis was reported by Süssmuth et al. in $2013,{ }^{[21]}$ and very recently, a second total synthesis by Ley and co-workers, ${ }^{[22]}$ both syntheses relying on classical peptide coupling. We now report a conceptually different synthesis of plantazolicin A based on carbene chemistry.

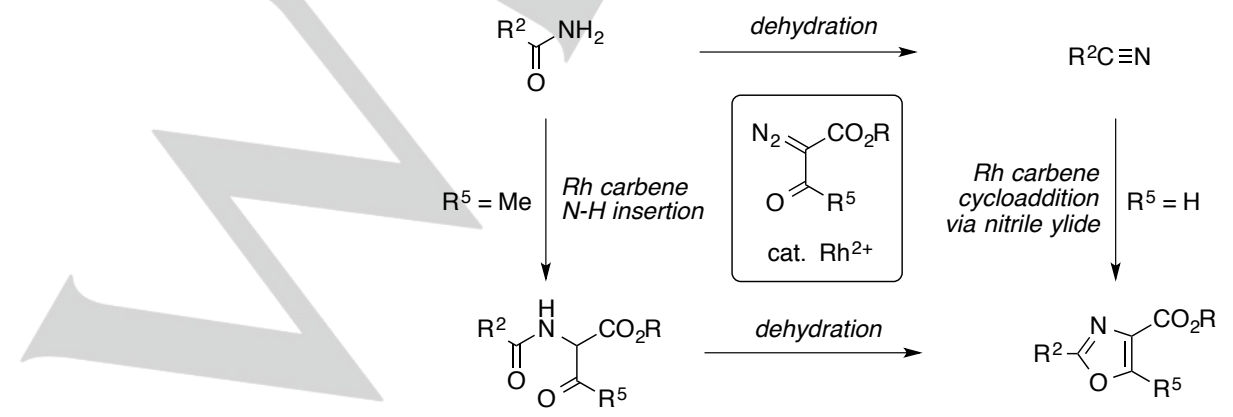

Scheme 1. Oxazoles from carboxamides and nitriles via rhodium carbenes. 
Our strategy was to construct the azole rings using the afore-mentioned carbene chemistry, and hence our retrosynthetic analysis divided the molecule into two fragments $\mathbf{3}$ and $\mathbf{4}$, each adorned with appropriate protecting groups, with the sensitive oxazoline ring in the $C$-terminus right hand fragment 4 to be formed by a late stage cyclodehydration reaction (Scheme 2). In contrast with other approaches, we elected to introduce the guanidine moiety later in the synthesis. Thus the starting point for our synthesis was the known ornithine-derived thiazole-4ester $5,{ }^{[23]}$ readily converted into the corresponding carboxamide 6 setting the scene for our first carbene step (Scheme 3). The key metallocarbene $\mathrm{N}-\mathrm{H}$ insertion was carried out by slow addition of methyl 2-diazo-3oxobutanoate to amide 6 in the presence of $2.5 \mathrm{~mol} \%$ of rhodium(II) acetate dimer in chloroform, to give the ketoamide 7, which was immediately cyclized to oxazole 8 by cyclodehydration with triphenylphosphine and iodine in the presence of base. ${ }^{[2]}$ However, it proved difficult to isolate the product from triphenylphosphine oxide, ameliorated by use of polymer-supported triphenylphosphine. The ester 8 was converted into the corresponding carboxamide 9 and hence the thiocarboxamide 10 by treatment with Lawesson's reagent. A Hantzsch reaction formed the next ring and delivered the three-azole array 11 (Scheme 3), and with two further oxazoles to install, an iterative carbene carboxamide $\mathrm{N}-\mathrm{H}$ insertion cyclodehydration sequence was instigated. Thus ester 11 was converted into carboxamide 12 that underwent the desired carbene insertion to give ketoamide 13, cyclodehydration of which gave tetra-azole 14 in $52 \%$ yield over two steps. A second iteration by way of carboxamide 15 and ketoamide 16 produced the desired penta-azole 17, although the yield of this last ringforming step was poor.

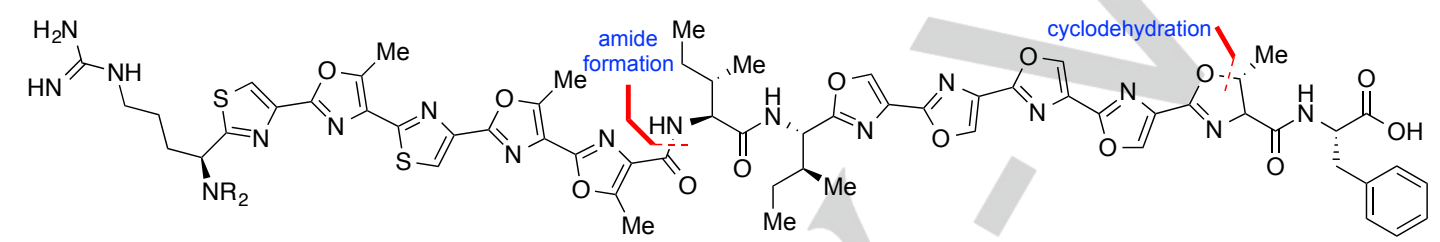

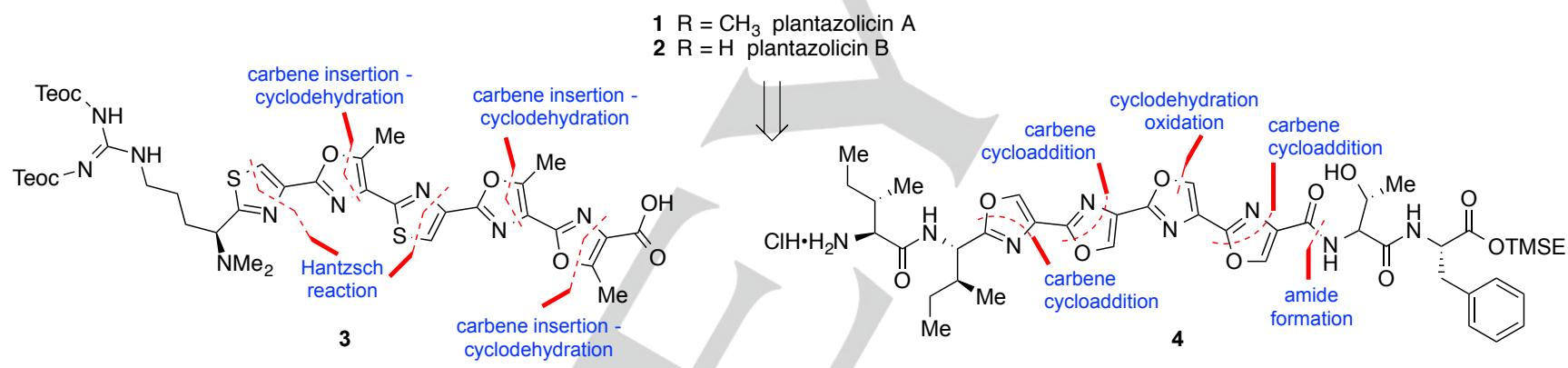

Scheme 2. Retrosynthetic analysis of plantazolicin A. 


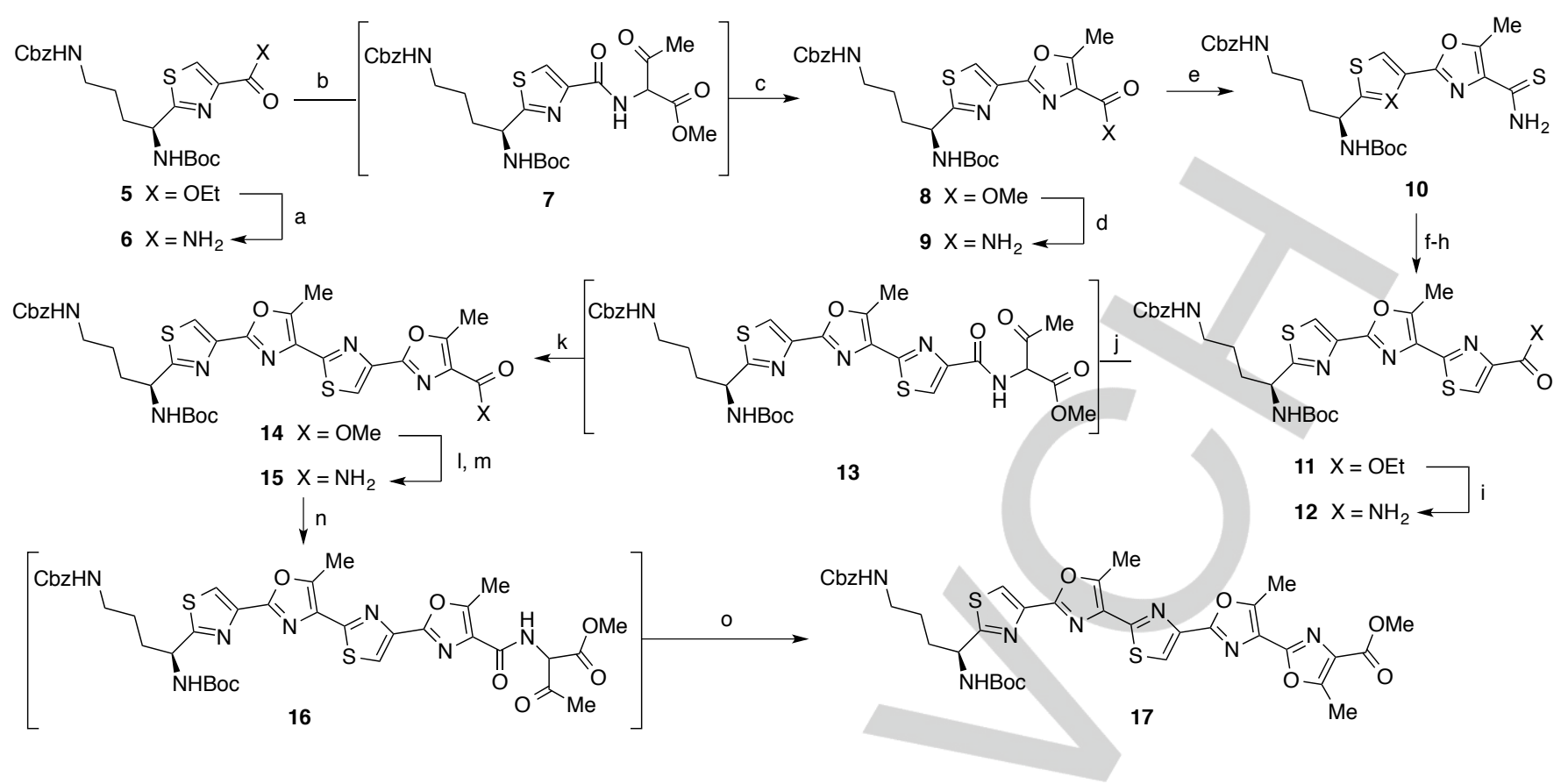

Scheme 3. Synthesis of intermediate penta-azole 17. Reagents and Conditions. a) $35 \%$ aq $\mathrm{NH}_{3}$ solution, $\mathrm{EtOH}$, $\mathrm{rt}, 93 \%$; b) methyl 2-diazo-3-oxobutanoate (1.4 equiv), rhodium(II) acetate dimer (2.5 mol\%), $\mathrm{CHCl}_{3}, 60^{\circ} \mathrm{C} ; \mathrm{c}$ ) Polymer-Ph ${ }_{3} \mathrm{P}$ (1.6 equiv), $\mathrm{I}_{2}$ (1.6 equiv), $\mathrm{Et}_{3} \mathrm{~N}$ (3.2 equiv), $\mathrm{CH}_{2} \mathrm{Cl}_{2}, \mathrm{rt}, 72 \%$ (2 steps); d) ammonia, $\mathrm{MeOOH}, \mathrm{THF}, \mathrm{rt}$, $80 \%$; e) Lawesson's reagent ( 0.7 equiv), $\mathrm{CHCl}_{3}, \mathrm{rt}, 55 \%$; f) ethyl bromopyruvate (5.0 equiv), $\mathrm{KHCO}_{3}(10$ equiv), $\left.\mathrm{DME},-10^{\circ} \mathrm{C} ; \mathrm{g}\right)$ trifluoroacetic anhydride (5 equiv), 2,6-lutidine (10 equiv), $\left.\mathrm{DME},-10{ }^{\circ} \mathrm{C} ; \mathrm{h}\right) \mathrm{K}_{2} \mathrm{CO}_{3}(5.0$ equiv), $\mathrm{EtOH}, \mathrm{H}_{2} \mathrm{O}, \mathrm{rt}, 71 \%$ (3 steps); i) $35 \%$ aq $\mathrm{NH}_{3}$ solution, $\mathrm{EtOH}, \mathrm{rt}, 84 \%$; j) methyl 2-diazo-3-oxobutanoate (1.4 equiv), rhodium(II) acetate dimer $(2.5 \mathrm{~mol} \%), \mathrm{CHCl}_{3}, 60{ }^{\circ} \mathrm{C} ; \mathrm{k}$ ) Polymer-Ph ${ }_{3} \mathrm{P}$ ( 3.5 equiv), $\mathrm{I}_{2}$ (3.5 equiv), $\mathrm{Et}_{3} \mathrm{~N}(7.0$ equiv), $\mathrm{CH}_{2} \mathrm{Cl}_{2}, \mathrm{rt}, 52 \%$ (2 steps); l) $\mathrm{LiOH}, \mathrm{MeOH}, \mathrm{THF}, \mathrm{rt}, 93 \%$; $\mathrm{m}$ ) $\mathrm{EtO}_{2} \mathrm{CCl}_{2} \mathrm{Et}_{3} \mathrm{~N}$, THF, $35 \%$ aq $\mathrm{NH}_{3}$ solution, rt, $57 \%$; n) methyl 2-diazo-3-oxobutanoate (1.4 equiv), rhodium(II) acetate dimer $\left.(2.5 \mathrm{~mol} \%), \mathrm{CHCl}_{3}, 60{ }^{\circ} \mathrm{C} ; 0\right)$ Polymer- $\mathrm{Ph}_{3} \mathrm{P}$ (4.0 equiv), $\mathrm{I}_{2}$ (4.0 equiv), $\mathrm{Et}_{3} \mathrm{~N}$ (8.0 equiv), $\mathrm{CH}_{2} \mathrm{Cl}_{2}, \mathrm{rt}, 11 \%$ (2 steps). [DME $=1,2-$ dimethoxyethane]

In view of the unsatisfactory formation of the fifth and final ring in the penta-azole 17, we sought an alternative, whilst still satisfying our desire to use carbene methodology to construct the azole rings. Thus the protected threoninamide 18 underwent rhodium(II) catalyzed $\mathrm{N}-\mathrm{H}$ insertion followed by cyclodehydration to give oxazole ester $\mathbf{2 0}$ in good yield, deprotection of which resulted in the free threonine-oxazole $\mathbf{2 1}$ (Scheme 4). This amine was then coupled with the thiazolecarboxylate derived by simple hydrolysis of the bis-thiazolyloxazole 11 resulting in the formation of the linear tetra-azole 22. Subsequent ring closure of the threonine fragment using DAST methodology gave oxazoline $2 \mathbf{2 3}^{[25]}$ dehydrogenative aromatization of which with the bromotrichloromethane protocol ${ }^{[26]}$ returned the previously prepared penta-azole 17 . With an improved route available to the key penta-azole available, the synthesis rapidly progressed towards the complete left-hand fragment 3 of the antibiotic. Acid mediated removal of the Boc-group allowed for installation of the dimethylamino group by a reductive amination reaction with formaldehyde to give 25 , which underwent cleavage of the

iterated to deliver the bis-oxazole ester $\mathbf{3 5}$ by conversion of oxazole ester $\mathbf{3 2}$ into nitrile $\mathbf{3 4}$ and thereafter a second rhodium carbene step. Meanwhile, nitrile $\mathbf{3 7}$ also underwent rhodium carbene cycloaddition to give oxazole $38,{ }^{[10]}$ which was deprotected to amine 39 in preparation for union with the bis-oxazole fragment. Bisoxazole ester $\mathbf{3 5}$ was hydrolyzed to acid $\mathbf{3 6}$, subsequently coupled to amine $\mathbf{3 9}$ under the HBTU protocol 

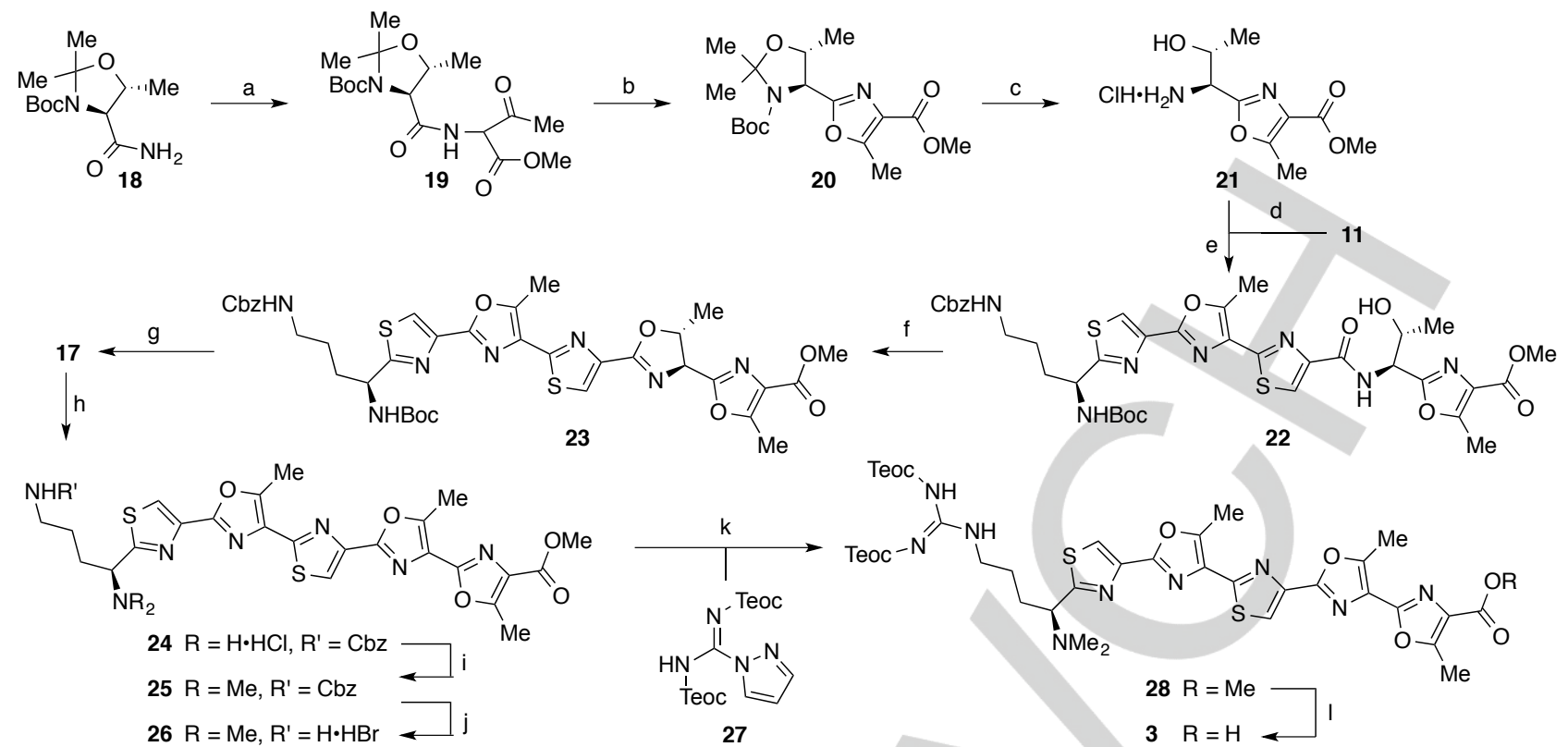

Me Tec ${ }^{\mathrm{NH}}$
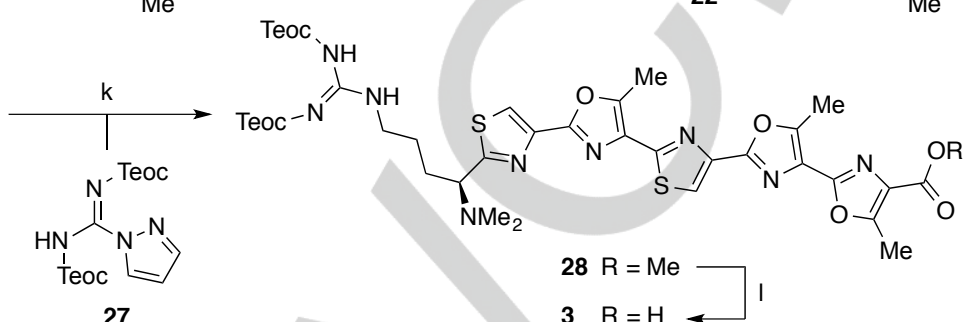

Scheme 4. Synthesis of left-hand penta-azole fragment 3. Reagents and Conditions. a) methyl 2-diazo-3oxobutanoate (1.4 equiv), rhodium(II) acetate dimer $(2.5 \mathrm{~mol} \%), \mathrm{CHCl}_{3}, 70^{\circ} \mathrm{C}, 16 \mathrm{~h}$, quant.; b) $\mathrm{Ph}_{3} \mathrm{P}$ (2.0 equiv), $\mathrm{I}_{2}$ (2.0 equiv), $\mathrm{Et}_{3} \mathrm{~N}$ (4.0 equiv), $\mathrm{CH}_{2} \mathrm{Cl}_{2}, \mathrm{rt}, 55 \%$; c) $4 \mathrm{M} \mathrm{HCl}$ in 1,4-dioxane, rt, $6 \mathrm{~h}$, quant.; d) LiOH, MeOH-THF$\mathrm{H}_{2} \mathrm{O}(1: 5: 5)$, rt, $15 \mathrm{~h}, 82 \%$; e) $\mathrm{HBTU}, \mathrm{Et}_{3} \mathrm{~N}, \mathrm{CH}_{2} \mathrm{Cl}_{2}, \mathrm{rt}, 92 \%$; f) DAST, $\mathrm{K}_{2} \mathrm{CO}_{3}, \mathrm{CH}_{2} \mathrm{Cl}_{2},-78 \mathrm{C}$; g) $\mathrm{BrCCl}_{3}, \mathrm{DBU}$, $\mathrm{CH}_{2} \mathrm{Cl}_{2}, 0{ }^{\circ} \mathrm{C}$-rt, $32 \%$; h) $4 \mathrm{M} \mathrm{HCl}$ in dioxane, rt, quant.; i) $\mathrm{NaOAC} \cdot 3 \mathrm{H}_{2} \mathrm{O}$ (56 equiv), formaldehyde ( $37 \%$ solution in $\mathrm{H}_{2} \mathrm{O}, 30$ equiv), $\mathrm{NaBH}_{3} \mathrm{CN}$ (23 equiv), THF, rt, $63 \%$; $\mathrm{j}$ ) $\mathrm{HBr}$ (33\% solution in $\mathrm{AcOH}$; 100 equiv), rt, quant.; $\mathrm{k}$ ) 27 (1.4 equiv), $\mathrm{Et}_{3} \mathrm{~N}$ (2.8 equiv), $\left.\mathrm{CHCl}_{3}, 40 \% ; \mathrm{l}\right) \mathrm{Me}_{3} \mathrm{SnOH}$ (10 equiv), $\mathrm{DCE}, 80^{\circ} \mathrm{C}$, quant. [HBTU = $(2-(1 \mathrm{H}-$ benzotriazol-1-yl)-1, 1,3,3-tetramethyluronium hexafluorophosphate; DAST = dimethylamino sulfur trifluoride; DBU $=$ 1,8-diazabicyclo[5.4.0]undec-7-ene; DCE = 1,2-dichloroethane]

remaining $\mathrm{N}$-protecting group in preparation for the introduction of the 2-trimethylsilylethoxycarbonyl (Teoc) protected guanidine onto amine $\mathbf{2 6}$. To this end, we developed a new reagent, the pyrazole carboxamidine $\mathbf{2 7}$, that successfully incorporated the protected guanidine to give penta-azole $\mathbf{2 8}$, which underwent final ester removal to give the desired fragment 3 (Scheme 4 ) in $1.2 \%$ overall yield over 17 steps.

The presence of four $\mathrm{C}-5$ unsubstituted oxazoles in the $C$-terminus fragment of the antibiotic, in contrast to the three 5-methyloxazoles present in the $\mathrm{N}$-terminal fragment $\mathbf{3}$, necessitated a slight change in methodology. Thus, the order of steps was reversed with the carboxamide being initially dehydrated to the nitrile, with subsequent direct conversion into the oxazole in the rhodium catalyzed carbene step (Scheme 1) ${ }^{[10,27]}$ Hence the synthesis of fragment 4 started with the known isoleucine-isoleucine dipeptide $29,{ }^{[28]}$ that was converted into the carboxamide 30 and hence the required nitrile 31 (Scheme 5). This set the stage for the direct installation of the first oxazole 32 by dirhodium(II)-catalyzed reaction with the formyl diazo compound, ethyl 2-diazo-3-oxopropanoate, although a change in catalyst to dirhodium tetrakis-(heptafluorobutyramide) was beneficial. ${ }^{[27]}$ The sequence was

to give adduct 40. A DAST-mediated cyclodehydration and aromatization completed the linear array $\mathbf{4 1}$ of four oxazoles, subsequently hydrolyzed to the corresponding carboxylic acid $\mathbf{4 2}$ for further elaboration (Scheme 5). Separately, Boc-Phe-OH was protected as its 2-trimethylsilylethyl (TMSE) ester 43, the Boc group cleaved and the ensuing amine $\mathbf{4 4}$ united with $\mathrm{N}$-Boc-allothreonine to give dipeptide $\mathbf{4 5}$. The dipeptide was deprotected in acid and the resulting amine $\mathbf{4 6}$ underwent coupling with the tetra-oxazole acid $\mathbf{4 2}$ to give, after removal of the Boc group, the complete C-terminal fragment 4 in 1.7\% overall yield over 13 steps from the isoleucine dipeptide 29.

With both the $\mathrm{N}$ - and $\mathrm{C}$-terminal halves of the antibiotic successfully obtained, polyazoles $\mathbf{3}$ and $\mathbf{4}$ were united in the presence of $\mathrm{HBTU}$ and $\mathrm{Et}_{3} \mathrm{~N}$ to give the coupled product $\mathbf{4 8}$. The threonine moiety of the intermediate 48 was cyclized in the presence of DAST to afford the oxazoline 49 , the ${ }^{1} \mathrm{H}$-NMR and ${ }^{13} \mathrm{C}$-NMR spectroscopic data of which matched an intermediate prepared in an earlier synthesis. ${ }^{[21]}$ All that remained was to remove the three silicon-based protecting group, and in common with previous workers, we found that this was not completely straightforward, and required a two-stage strategy involving sequential use of two fluoride based reagents to complete the 


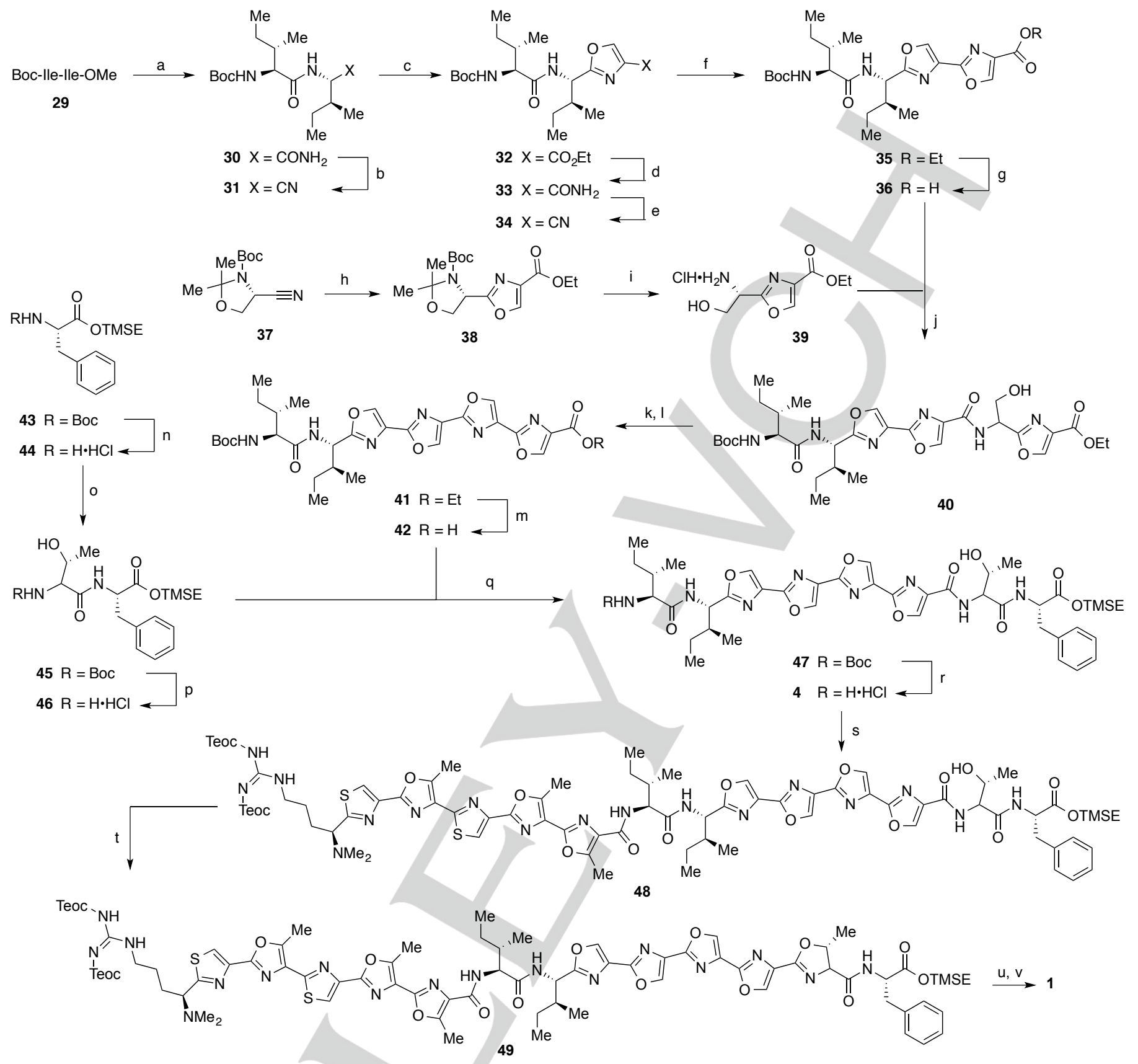

Scheme 5. Synthesis of right-hand tetra-azole fragment 4. Reagents and Conditions. a) ammonia, MeOH, THF, $\mathrm{rt}, 76 \%$; b) DBU (5.0 equiv), ethyl dichlorophosphate (3.0 equiv), $\mathrm{CH}_{2} \mathrm{Cl}_{2}, 0{ }^{\circ} \mathrm{C}, 80 \%$; c) ethyl 2-diazo-3oxopropanoate (3.0 equiv), rhodium(II) perfluorobutyramide dimer $\left(2.5\right.$ mol\%), $\mathrm{CHCl}_{3}, 60{ }^{\circ} \mathrm{C}, 53 \%$; d) ammonia, $\mathrm{EtOH}, \mathrm{THF}, \mathrm{rt}, 89 \%$; e) DBU (5.0 equiv), ethyl dichlorophosphate (3.0 equiv), $\mathrm{CH}_{2} \mathrm{Cl}_{2}, 0{ }^{\circ} \mathrm{C}, 79 \%$; f) ethyl 2-diazo3-oxopropanoate (3.0 equiv), rhodium(II) perfluorobutyramide dimer $\left.(2.5 \mathrm{~mol} \%), \mathrm{CHCl}_{3}, 60{ }^{\circ} \mathrm{C}, 59 \% ; \mathrm{g}\right) \mathrm{LiOH}(58$ equiv), $\mathrm{H}_{2} \mathrm{O}, \mathrm{EtOH}, \mathrm{THF}, \mathrm{rt}, 65 \%$; h) ethyl 2-diazo-3-oxopropanoate (3.0 equiv), rhodium(II) perfluorobutyramide dimer (2.5 mol\%), $\mathrm{CHCl}_{3}, 60{ }^{\circ} \mathrm{C}, 51 \%$; i) $2 \mathrm{M} \mathrm{HCl}$ in ether, rt, quant; j) $\mathrm{HBTU}$ (1.5 equiv), 39 (1.5 equiv), $\mathrm{Et} 3 \mathrm{~N}$ (2.0 equiv), $\mathrm{CH}_{2} \mathrm{Cl}_{2}$-DMF, rt, $76 \%$; k) DAST (1.7 equiv), $\mathrm{K}_{2} \mathrm{CO}_{3}$ (5.0 equiv), $\mathrm{CH}_{2} \mathrm{Cl}_{2},-78{ }^{\circ} \mathrm{C}$, quant; I) $\mathrm{BrCCl}_{3}$ (4.0 equiv), DBU ( 4.0 equiv), $\mathrm{CH}_{2} \mathrm{Cl}_{2}, 0{ }^{\circ} \mathrm{C}, 59 \%$ (2 steps); $\mathrm{m}$ ) $\mathrm{LiOH}$ (29 equiv), $\mathrm{H}_{2} \mathrm{O}$, EtOH, THF, rt, $76 \%$; $\mathrm{n}$ ) $4 \mathrm{M} \mathrm{HCl}$ in dioxane, rt, 56\%; o) Boc allothreonine (1.0 equiv), $\mathrm{HBTU}$ (2.0 equiv), 44 (2.0 equiv), $\mathrm{Et}_{3} \mathrm{~N}^{(4.0}$ equiv), $\mathrm{CH}_{2} \mathrm{Cl}_{2}-$ DMF, rt, $65 \%$; p) $4 \mathrm{M} \mathrm{HCl}$ in dioxane, rt, $79 \%$; q) $\mathrm{HBTU}$ (1.5 equiv), 46 (1.5 equiv), $\mathrm{Et}_{3} \mathrm{~N}$ (3.0 equiv), $\mathrm{CH}_{2} \mathrm{Cl}_{2}-\mathrm{DMF}$ $\mathrm{rt}, 58 \% ; r$ ) $4 \mathrm{M} \mathrm{HCl}$ in dioxane, rt, quant; s) HBTU (1.3 equiv), $3, \mathrm{Et}_{3} \mathrm{~N}$ (2.4 equiv), $\mathrm{CH}_{2} \mathrm{Cl}_{2}, \mathrm{rt}, 50 \% ; \mathrm{t}$ ) DAST (30.0 equiv.), $\mathrm{CH}_{2} \mathrm{Cl}_{2},-10{ }^{\circ} \mathrm{C}, 52 \%$; u) TASF (30.0 equiv.), DMSO, rt; v) HFIP, rt, $31 \%$. [TMSE = 2-trimethylsilylethyl; TASF $=$ tris(dimethylamino)sulfonium difluorotrimethylsilicate; HFIP = hexafluoroisopropanol] 
total synthesis (Scheme 5). Following purification by HPLC, the NMR spectroscopic data of our synthetic material matched those reported for the natural antibiotic (Tables S1 and S2); the compound also co-eluted on HPLC with authentic material (Figures S1-S3). Our synthetic material also exhibited modest potency against methicillinresistant Staphylococcus aureus (MRSA) with an MIC $>33 \mu \mathrm{g} / \mathrm{mL}\left(\right.$ cf. $>128 \mu \mathrm{g} / \mathrm{mL}^{[13]}$ ).

Finally, we were interested in the conformation of plantazolicin A. NMR spectroscopy NOESY and TOCSY experiments were carried out (see $\mathrm{SI}$ ) along with molecular modeling. The lack of long range NOEs suggests a moderately dynamic molecule with rigid oxazole/thiazole arms that are not in close contact for any appreciable time. However, the strong NOEs around the central two isoleucine residues suggest this could act as a hinge region leading to a dynamic hair pin conformation. A structure consistent with these data is shown in Figure 1.

The carbene-based synthesis described above is not only a practical route to provide further quantities of the fascinating antimicrobial agent plantazolicin $\mathrm{A}$, it also makes available a wide range fragment structures and analogues that are not available by Nature's biosynthetic machinery. The full biological evaluation of these novel structures is underway.

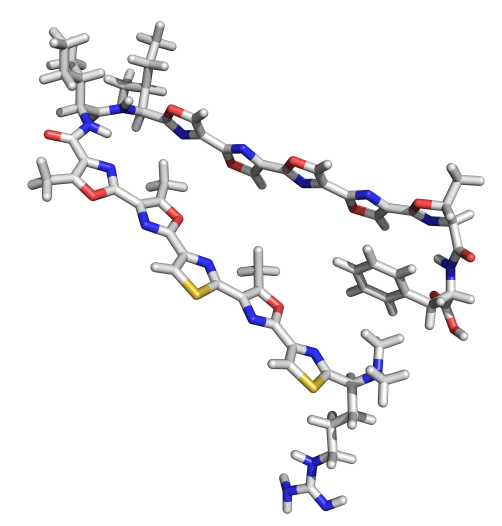

Figure 1. Most probable conformation of plantazolicin A based on NMR spectroscopy and molecular modeling.

\section{Experimental Section}

All experimental procedures, characterization data for all compounds and copies of the ${ }^{1} \mathrm{H}$ and ${ }^{13} \mathrm{C}$ NMR spectra are given in the Supporting Information associated with this paper.

\section{Acknowledgements}

We thank AstraZeneca for a Sten Gustafsson Scholarship to H.W. and the University of Nottingham for financial support, Dr Ewan Murray and Professor Paul Williams (University of Nottingham School of Life Sciences) for biological data, and Dr Zoe Wilson and Professor Steven Ley (University of Cambridge) for a sample of plantazolicin A.

Keywords: antibiotic $\bullet$ synthesis $\bullet$ heterocyclic compound $\bullet$ diazo compound $\bullet$ carbenes

[1] A. Kekulé, Liebigs Ann. Chem. 1858, 106, 129-159.

[2] A. S. Couper, Ann. Chim. Phys. 1858, 53, 469-489.

[3] A. Igau, H. Grützmacher, A. Baceiredo, G. Bertrand, J. Am. Chem. Soc. 1988, 110, 6463-6466.

[4] A. J. Arduengo, R. L. Harlow, M.Kline, J. Am. Chem. Soc. 1991, 113, 361-363.

[5] M. N. Hopkinson, C. Richter, M. Schedler, F. Glorius, Nature 2014, 510, 485-496.

[6] M. P. Doyle, M. A. McKervey, T. Ye, Modern Catalytic Methods for Organic Synthesis with Diazo Compounds, John Wiley, New York, 1998.

[7] M. C. Bagley, K. E. Bashford, C. L. Hesketh, C. J. Moody, J. Am. Chem. Soc. 2000, 122, 3301-3313.

[8] R. A. Hughes, S. P. Thompson, L. Alcaraz, C. J. Moody, J. Am. Chem. Soc. 2005, 127, 15644-15651.

[9] J. Linder, C. J. Moody, Chem. Commun. 2007, 1508-1509.

[10] J. Linder, T. P. Garner, H. E. L. Williams, M. S. Searle, C. J. Moody, J. Am. Chem. Soc. 2011, 133, 10441051. 
[11] R. Scholz, K. J. Molohon, J. Nachtigall, J. Vater, A. L. Markley, R. D. Süssmuth, D. A. Mitchell, R. Borriss, J. Bacteriol. 2011, 193, 215-224.

[12] B. Kalyon, S. E. Helaly, R. Scholz, J. Nachtigall, J. Vater, R. Borriss, R. D. Süssmuth, Org. Lett. 2011, 13, 2996-2999.

[13] K. J. Molohon, J. O. Melby, J. Lee, B. S. Evans, K. L. Dunbar, S. B. Bumpus, N. L. Kelleher, D. A. Mitchell, ACS Chem. Biol. 2011, 6, 1307-1313.

[14] C. D. Deane, J. O. Melby, K. J. Molohon, A. R. Susarrey, D. A. Mitchell, ACS Chem. Biol. 2013, 8, 19982008.

[15] N. A. Piwowarska, S. Banala, H. S. Overkleeft, R. D. Suessmuth, Chem. Commun. 2013, 49, 10703-10705.

[16] M. C. Bagley, J. W. Dale, E. A. Merritt, X. Xiong, Chem. Rev. 2005, 105, 685-714.

[17] R. A. Hughes, C. J. Moody, Angew. Chem. Int. Ed. 2007, 46, 7930-7954.

[18] X. Just-Baringo, F. Albericio, M. Alvarez, Angew. Chem. Int. Ed. 2014, 53, 6602-6616.

[19] M. J. LaMarche, J. A. Leeds, A. Amaral, J. T. Brewer, S. M. Bushell, G. Deng, J. M. Dewhurst, J. Ding, J. Dzink-Fox, G. Gamber, A. Jain, K. Lee, L. Lee, T. Lister, D. McKenney, S. Mullin, C. Osborne, D. Palestrant, M. A. Patane, E. M. Rann, M. Sachdeva, J. Shao, S. Tiamfook, A. Trzasko, L. Whitehead, A. Yifru, D. Yu, W. Yan, Q. Zhu, J. Med. Chem. 2012, 55, 2376-2387.

[20] J. A. Leeds, M. Sachdeva, S. Mullin, J. Dzink-Fox, M. J. LaMarche, Antimicrob. Agents Chemother. 2012, 56, 4463-4465.

[21] S. Banala, P. Ensle, R. D. Süssmuth, Angew. Chem. Int. Ed. 2013, 52, 9518-9523.

[22] Z. E. Wilson, S. Fenner, S. V. Ley, Angew. Chem. Int. Ed. 2015, 54, 1284-1288.

[23] G. Pattenden, T. Thompson, Chem. Commun. 2001, 717-718.

[24] P. Wipf, C. P. Miller, J. Org. Chem. 1993, 58, 3604-3606.

[25] A. J. Phillips, Y. Uto, P. Wipf, M. J. Reno, D. R. Williams, Org. Lett. 2000, 2, 1165-1168.

[26] D. R. Williams, P. D. Lowder, Y. G. Gu, D. A. Brooks, Tetrahedron Lett. 1997, 38, 331-334.

[27] K. J. Doyle, C. J. Moody, Synthesis 1994, 1021-1022.

[28] N. Umezawa, N. Matsumoto, S. Iwama, N. Kato, T. Higuchi, Bioorg. Med. Chem. 2010, $18,6340-6350$. 


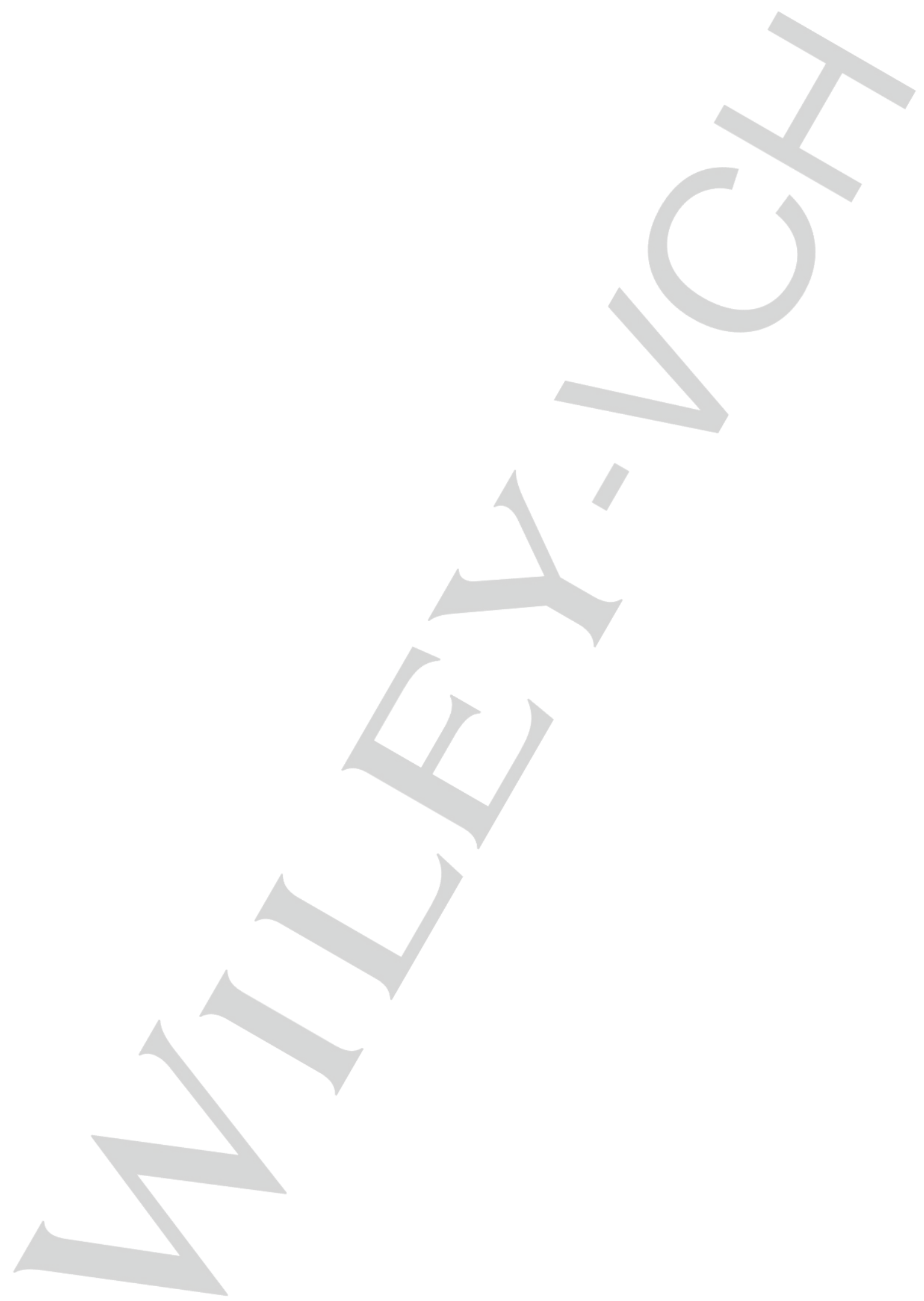

